\title{
Paediatric presentation of type 2 neurofibromatosis
}

\author{
D G R Evans, J M Birch, R T Ramsden
}

\begin{abstract}
Background-Neurofibromatosis type 2 (NF2) is a highly penetrant autosomal dominant condition predisposing affected individuals to schwannomas and meningiomas. The proportion of children presenting with meningioma or schwannoma who have NF2 is not well described, and neither is the mode of presentation in most children with the inherited disease.

Aims-To determine the frequency of childhood meningioma and schwannoma cases caused by NF2 and the mode of presentation.

Methods-The records of the Manchester Children's Tumour Registry from 1954 were searched for cases of meningioma and schwannoma. Paediatric presentation in a large UK series of NF2 was also studied. Results-18\% (61/334) of patients with NF2 on the UK database presented in the paediatric age group (0-15 years), frequently with the symptoms of an isolated tumour. More than half had no family history to alert the clinician to their susceptibility. Three of 22 children presenting with a meningioma on the Manchester Children's Tumour Registry have gone on to develop classic features of NF2.

Conclusions-Clinicians should suspect NF2 in children presenting with meningioma, schwannoma, and skin features, such as neurofibromas/schwannomas, but fewer than 6 café au lait patches, who thus fall short of a diagnosis of neurofibromatosis type 1 .

(Arch Dis Child 1999;81:496-499)
\end{abstract}

Department of

Medical Genetics

St Mary's Hospital,

Manchester M13 0JH,

UK

D G R Evans

CRC Paediatric and Familial Cancer Research Group, Royal Manchester Children's Hospital, Manchester M27 4HA, UK

J M Birch

Department of Otolaryngology, Manchester Royal Infirmary, Oxford

Road, Manchester M13 9WL, UK

R T Ramsden

Correspondence to: Dr Evans

Accepted 13 July 1999
Keywords: neurofibromatosis type 2; meningioma; schwannoma; facial paralysis

Neurofibromatosis type 2 (NF2) was first described in 1820 by the Scottish surgeon JH Wishart. ${ }^{1}$ Since that time, NF2 became inextricably linked with the more common type of neurofibromatosis (type 1), which was first fully delineated by von Recklinghausen in the late $1800 \mathrm{s.}^{2}$ Many reports of individuals and families with bilateral vestibular schwannomas, the cardinal feature of NF2, appeared in the early 20th century. However, the assertion of such a prominent individual as Harvey Cushing $^{3}$ that acoustic neuromas (the previous name for vestibular schwannomas) were part of the spectrum of von Recklinghausen's disease meant that it took until 1987, when the two diseases were localised to separate chromosomal locations, ${ }^{45}$ for a formal delineation to occur. $^{6}$ It is now difficult to understand why $\mathrm{NF} 1$ and NF2 became so intertwined. The main tumour types of NF2, schwannomas of the cranial, spinal, and cutaneous nerves and cranial or spinal meningiomas, do not occur more frequently in NF1 than in the general population. ${ }^{78}$ Neurofibromas are not common in NF2 and the cutaneous features very rarely fulfil the consensus criteria for the diagnosis of NF1. However, both diseases have a considerable impact in childhood, but the presentation of NF2 in childhood is not well described. The childhood presentation from a large UK dataset of patients with NF2 is presented alongside a long term follow up study on children presenting with meningioma or schwannoma in the north west of England.

\section{Patients and methods}

A database recording information on affected individuals with NF2 was set up in Manchester in 1989. Patients were actively sought across the UK from paediatricians, neurosurgeons, "ear, nose, and throat" surgeons, geneticists, and dermatologists. Patient details from hospital notes and proformas gathered from around the UK have been entered on to a database at St Mary's Hospital, Manchester since 1989. A total of 334 patients fulfilling our published criteria for NF2 are recorded (table 1), with 285 patients alive on 1 January 1999 . One of us (DGRE) has personally seen over 220 of the patients. Information on all known tumours, age at presentation and diagnosis, and many different symptoms are included. All patients presenting with a classic feature of NF2 (table 1) under 16 years of age have been included in our study. The presenting feature and other features of NF2 at diagnosis of the primary feature have been analysed. The proportion presenting with each feature over the first 15 years of life was calculated. In particular, the proportion presenting initially with an isolated problem was assessed.

\section{The Manchester Children's Tumour} Registry

The Manchester Children's Tumour Registry is an active, prospective, notes based recording system for all children presenting with a

Table 1 Diagnostic criteria for neurofibromatosis type 2 (NF2)

Bilateral vestibular schwannomas or family history of NF2 plus (1) Unilateral vestibular schwannoma

(2) Any two of: meningioma, glioma, neurofibroma schwannoma, posterior subcapsular lenticular opacities

Additional criteria

(1) Unilateral vestibular schwannomas + any two of: meningioma, glioma, neurofibroma, schwannoma, and posterior subcapsular opacities

(2) Multiple meningioma (two or more) + unilateral

vestibular schwannoma or any two of: glioma, neurofibroma, schwannoma, and cataract 
Table 2 Clinical features in children presenting with neurofibromatosis type 2 (NF2) aged 10 years or less

\begin{tabular}{|c|c|c|c|c|c|c|c|c|}
\hline Case & Sex & $\begin{array}{l}\text { Age at first } \\
\text { symptom } \\
\text { (years) }\end{array}$ & $\begin{array}{l}\text { Age at } \\
\text { diagnosis } \\
\text { (years) }\end{array}$ & First symptom & NF2 feature & $\begin{array}{l}\text { Delay to VS } \\
\text { (years) }\end{array}$ & Inheritance & Mutation \\
\hline 1 & M & 0.75 & 1.25 & Seizures & Meningioma & $14(\mathrm{np})$ & NM & Yes \\
\hline 2 & $M$ & 0.65 & 2 & Nystagmus & Ret hamart & $3(\mathrm{np})$ & NM & No \\
\hline 3 & M & 1.25 & 4 & Weight loss & Glioma & 1 & NM & No \\
\hline 4 & M & 1.3 & 6 & Visual loss & Meningioma & 5 & NM & Yes \\
\hline 5 & $M$ & 2 & 18 & Weakness & Spinal schw & $18(\mathrm{np})$ & Mat & Yes \\
\hline 6 & M & 2 & 15 & Headaches & Meningioma & 11 & NM & Yes \\
\hline 7 & $M$ & 3 & 5 & Facial palsy & VS & - & Mat & Yes \\
\hline 8 & $M$ & 3 & 4 & Deafness & Meningioma & 14 & Pat & Yes \\
\hline 9 & $\mathrm{~F}$ & 4 & 47 & Skin lumps & Cut schw & 43 & NM & NT \\
\hline 10 & $M$ & 4 & 11 & Deafness & VS & - & NM & No \\
\hline 11 & M & 5 & 5 & Visual loss & Meningioma & - & NM & NT \\
\hline 12 & M & 5 & 23 & Visual loss & Meningioma & 18 & NM & No \\
\hline 13 & M & 5 & 11 & Seizures & Meningioma & $16(\mathrm{np})$ & Mat & No \\
\hline 14 & $\mathrm{~F}$ & 6 & 33 & Weakness & Spinal schw & 25 & Mat & No \\
\hline 15 & $\mathrm{~F}$ & 6 & 22 & Seizures & Meningioma & $26(\mathrm{np})$ & Pat & Yes \\
\hline 16 & $\mathrm{~F}$ & 6 & 6 & Weakness & Neuropathy & 1 & Pat & Yes \\
\hline 17 & $\mathrm{~F}$ & 6 & 23 & Deafness & VS & - & NM & Yes \\
\hline 18 & $\mathrm{~F}$ & 7 & 16 & Seizures & VS & - & NM & No \\
\hline 19 & M & 7 & 23 & Tinnitus & VS & - & NM & No \\
\hline 20 & $\mathrm{~F}$ & 7 & 9 & Facial palsy & VS & - & NM & No \\
\hline 21 & M & 7 & 8 & Facial palsy & VS & - & NM & Yes \\
\hline 22 & $\mathrm{~F}$ & 7 & 14 & Facial palsy & ?VS & - & NM & No \\
\hline 23 & $\mathrm{~F}$ & 8 & 20 & Facial palsy & ?VS & - & Mat & No \\
\hline 24 & M & 8 & 15 & Seizures & Meningioma & 7 & NM & NT \\
\hline 25 & $M$ & 8 & 8 & Seizures & Cranial calc & 9 & Mat & Yes \\
\hline 26 & M & 9 & 18 & Headaches & Meningioma & 9 & NM & Yes \\
\hline 27 & $M$ & 10 & 10 & Seizures & Meningioma & - & NM & No \\
\hline 28 & $\mathrm{~F}$ & 10 & 31 & Deafness & VS & - & NM & Yes \\
\hline 29 & M & 10 & 18 & Seizures & Meningioma & 8 & Pat & No \\
\hline 30 & $\mathrm{~F}$ & 10 & 21 & Paraesthesia & Spinal schw & 11 & NM & NT \\
\hline
\end{tabular}

VS, vestibular schwannoma; np, VS not present; NM, new mutation; Mat, maternal; Pat, paternal; NT, not tested; schw, schwannoma; calc, calcification; cut, cutaneous; Ret hamart, retinal hamartoma.

tumour in childhood in a defined population area. A panel of paediatric pathologists reviews all pathology, and ongoing follow up is assured by contact with the managing clinicians, hospital notes, and primary care physicians. Information was sought on all children registered with the Manchester Children's Tumour Registry since 1954 with a diagnosis of meningioma or schwannoma. The Manchester Children's Tumour Registry notes were scrutinised for family history of nerve related tumours and any further NF2 disease criteria since initial diagnosis.

\section{Results}

Sixty one of $334(18 \%)$ of the individuals on the NF2 database have presented with symptoms of the disease aged 15 years or less (table 2). Only 26 of these 61 patients presented initially with features consistent with vestibular schwannomas (hearing loss, tinnitus, and facial palsy), whereas 19 presented with symptoms of a meningioma, seven with a spinal tumour, and five with a cutaneous tumour. Six children presented with a unilateral facial palsy. Facial paralysis is an uncommon presentation of vestibular schwannomas and because the initial diagnosis was as

Table 3 Patients with neurofibromatosis type 2 (NF2) on the Manchester Children's Tumour Registry

\begin{tabular}{llllll}
\hline Case & Sex & $\begin{array}{l}\text { Age at } \\
\text { presentation }\end{array}$ & $\begin{array}{l}\text { Age at next NF2 } \\
\text { problem }\end{array}$ & Age at NF2 diagnosis & Tumours at diagnosis \\
\hline 1 & M & 9 & 15 (spinal schw) & 18 & $\begin{array}{l}\text { 2 meningiomas } \\
\text { Bilateral VS } \\
\text { Spinal schw }\end{array}$ \\
2 & F & 10 & 21 (VS) & 21 & $\begin{array}{l}\text { 3 meningiomas } \\
\text { VS }\end{array}$ \\
3 & M & 12 & 17 (VS) & 17 , died aged 20 & $\begin{array}{l}\text { 4 meningiomas } \\
\text { Bilateral VS }\end{array}$ \\
\hline
\end{tabular}

All ages in years.

VS, vestibular schwannoma; schw, schwannoma. long as 15 years ago it is possible that the palsy was the result of mononeuropathy in some cases. Two cases presented with a foot drop that did not fully recover. In one of these children the spinal magnetic resonance imaging (MRI) scan was normal. Twenty were diagnosed initially with an isolated non-vestibular schwannoma feature of NF2, over half of these with no previous family history of the disease. Thirteen of the 25 children tested for mutations that presented aged 10 years or younger had an identifiable NF2 mutation.

THE MANCHESTER CHILDREN'S TUMOUR REGISTRY Since 1954, a total of 22 children with meningioma have been recorded on the Manchester Children's Tumour Registry database. The median age at diagnosis was 9 years, with a range of 1 week to 14.5 years. Patient follow up has been recorded for a mean of 9 years (range 0.1-31). Nine children have died (aged 1.5-20 years), between 0 and 14.5 years after diagnosis. Three individuals presenting initially with an isolated meningioma have gone on to develop classic features of NF2, fulfilling our established criteria (tables 1 and 3), six, nine, and 11 years after diagnosis of their isolated meningioma. A fourth patient has developed further meningiomas and may well have NF2 because she was only 9 years at last follow up. None of these children had family histories suggestive of NF2.

Only 12 cases of schwannoma have been recorded since 1954 . Four of these were malignant and eight benign. Median age at diagnosis was 10 years (range, $0-14$ ). Follow up has been for a mean of 10.2 years (range, $0-30$ ). Three children have died $0,1.5$, and 9 years after diagnosis aged 0 (birth), 8.5, and 14 years, all from malignant tumours. Only one patient has 
been diagnosed with NF2 (case 1; table 3) and he had previously been diagnosed with a meningioma. The only family history suggestive of NF2 was present in the father of the child with a malignant schwannoma at birth. He had a schwannoma himself.

\section{Discussion}

To our knowledge, the UK NF2 database is the largest clinical database of NF2 in the world. Although ascertainment for the whole UK is not complete, the living diagnostic prevalence of 285 comes close to the one in 200000 we previously calculated from our own population in the north west. ${ }^{9}$ Therefore, this patient series comes close to a population based series of children presenting with NF2. Although NF2 is often considered to be an adult onset disease that is not relevant to the paediatric population, our series shows that at least $18 \%$ of NF2 sufferers present in childhood, and that many of these present with an isolated feature of the disease with no family history. We have also shown that $10-18 \%$ of children presenting with a meningioma or schwannoma are likely to have NF2 and prolonged follow up may be necessary. NF2 patients who present in childhood are likely to have a more severe disease course with multiple tumour disease. ${ }^{10}{ }^{11}$ This can partly be explained by the type of mutation in the NF2 gene. ${ }^{12-15}$ Individuals and families with mutations that truncate the protein product, such as nonsense or frameshift mutations, are associated with earlier onset and multiple tumours. It has also been reported that the detection rate for mutations is lower in isolated cases $^{16}{ }^{17}$ because the predisposing mutation is present in only a proportion of cells from the affected individual. This mosaicism is less likely in severely affected patients and the detection rate in sporadically affected children is higher. ${ }^{16}{ }^{17}$ Just over half of the children presenting at age 10 years or younger had a detectable mutation, which is higher than our previously reported detection rate for our total NF2 database. ${ }^{14}$

The pattern of presentation in children aged 10 years or under is very different from adult onset. Hearing loss or tinnitus was the presenting symptom in only $20 \%$ of children in this report, whereas these symptoms are the usual first feature in most large predominantly adult clinical series, including our own. ${ }^{10}{ }^{11}$ The high percentage of facial paralysis at presentation is curious. In a large personal series of more than 650 histologically confirmed vestibular schwannomas in adult patients the frequency of facial weakness as the presenting symptom was no greater than 2\% (RT Ramsden, unpublished data, 1999). If a cerebello-pontine angle lesion does present with facial paralysis, most clinicians would suspect a diagnosis other than vestibular schwannoma (for example, meningioma, glioma, or cholesteatoma). Facial nerve schwannomas can present with paralysis, and this is a tumour that does occur in NF2. ${ }^{10}$ However, the length of interval between the onset of the facial weakness and the eventual diagnosis of the cerebello-pontine angle tumour (up to 15 years) make it unlikely that

\section{Key messages}

- Children presenting with meningioma or schwannoma should be suspected of having neurofibromatosis type 2 (NF2)

- NF2 is a severe debilitating disease, which is worse with childhood onset

- Screening programmes for children of affected parents and of individuals with an NF2 related tumour in childhood have now been established

- Presymptomatic genetic testing for children at risk of NF2 is now possible in most families

the tumour, either vestibular schwannoma or meningioma, was responsible. Mononeuropathy and a more widespread peripheral neuropathy is now a well recognised feature of NF2 ${ }^{10}{ }^{11}$ It is possible that this is the cause of at least some of the facial palsies occurring in childhood because the frequency of this is far greater than would be expected from idiopathic (Bell's) palsy in childhood. It is also of note that two of the patients from our series presented with a foot drop, which in one case was not shown to be caused by a spinal tumour. We have previously alluded to a number of patients who had apparently been diagnosed with polio in childhood, after developing weakness and wasting of one leg. ${ }^{10}$ Because there was no prodromal illness, and at least one had been previously vaccinated, it is possible that this feature of a neuropathy in one limb is also part of the NF2 spectrum. The other striking feature is the delay from the first childhood symptom to the eventual diagnosis of NF2. It is likely that with greater awareness of the possible diagnosis this interval will be reduced. Awareness would reduce the delay in diagnosis of large difficult to treat vestibular schwannomas, such as was seen in case 3 (table 3 ).

A child who presents with NF2 with no family history is likely to have a new mutation of the NF2 gene. If there is no suggestive family history the risks to parent and siblings are low (probably less than 1\%). There are no such cases of two affected siblings without affected parents or parents being affected after children on the database. When an individual is diagnosed with NF2 he/she will need ongoing follow up to optimise care. It is clear that patients with NF2 fare better if they are managed in specialist centres, where surgery and other measures such as radiosurgery can be offered at the appropriate time. ${ }^{18}$ In experienced hands, hearing can be preserved with removal of vestibular schwannomas, and rehabilitation is now possible with auditory brain stem implants and, on occasion, cochlear implants. ${ }^{1920}$ Children of affected patients should be considered to be at $50 \%$ risk of NF2 and screening for NF2 should start at birth. ${ }^{21}$ Cataracts can affect vision in early life and a neonatal examination to detect these is a wise precaution. Other tumour implications are present in the first 10 years of life. Formal 
screening for vestibular schwannomas should start at 10 years because it is rare for tumours to occur before that time. Audiological tests including auditory brain stem responses are still a useful adjunct to MRI. MRI with gadolinium enhancement can detect tumours of $1-2 \mathrm{~mm}$ in size. Because surgery would only be contemplated for tumours of approximately $6 \mathrm{~mm}$ and tumour growth averages $2 \mathrm{~mm} /$ year, screening every three years in an individual with no tumours is probably sufficient. Once tumours are present screening should probably be annual. Spinal tumours are found very frequently on MRI; with as many as $90 \%$ of patients having evidence of these in some studies. ${ }^{22}$ However, only $25-30 \%$ require a spinal operation as a result of a symptomatic tumour. ${ }^{10}$ Nonetheless, a full annual neurological examination is probably a wise precaution. Baseline MRI scans in NF2 depend on the mutation type and disease course in the family, but should probably be arranged between 12 and 16 years of age. In most families, it is now possible to develop a genetic test so screening can be targeted on affected individuals only. Uptake of such testing in childhood and adult life is high. ${ }^{23}$

For children presenting with an isolated schwannoma or meningioma, full craniospinal imaging with MRI is advisable. A full clinical examination including cutaneous and slit lamp examination of eyes for cataracts can detect subtle features. Mutation analysis on blood samples cannot rule out NF2, but by combining tumour and blood analysis the risk of NF2 can be greatly reduced. Isolation of both mutational hits to the NF2 gene in the tumour and exclusion of these in blood rules out all but a relatively small risk of mosaicism. ${ }^{24} \mathrm{~A}$ child with an isolated tumour in whom mutation analysis of blood/tumour pair is conclusive can probably be removed from ongoing screening. Without a conclusive DNA result, follow up of at risk individuals in a similar way to children of an affected parent should be instituted.

\section{CONCLUSION}

Clinicians should suspect NF2 in children presenting with meningioma, schwannoma, and skin features, such as neurofibromas/ schwannomas, but fewer than six café au lait patches, who thus fall short of a diagnosis of NF1. NF2 is a severe debilitating disease, which is worse with childhood onset. Children with NF2 should be managed in supraregional specialist centres with an established interest in the disease. Screening programmes for children of affected parents and of individuals with an NF2 related tumour in childhood have now been established.

The Manchester Children's Tumour Registry is supported by the Cancer Research Campaign. JMB is a Cancer Research Campaign professorial research fellow.

1 Wishart JH. Case of tumours in the skull, dura mater, and brain. Edinburgh Med Surg f 1820;18:393-7.

2 Von Recklinghausen F. Ueber die multiplen Fibroma der Haut und ihre Beziehung zu den multiplen Neuromen. Berlin: A Hirschwald, 1882 .

3 Cushing H. Tumors of the nervus acusticus and the syndrome of the cerebello-pontile angle. Philadelphia: WB Saunders, 1917. 4 Rouleau G, Seizinger BR, Ozelius LG, et al. Genetic linkage analysis of bilateral acoustic neurofibromatosis to a DNA marker on chromosome 22. Nature 1987;329:246-8.

5 Seizinger BR, Rouleau GA, Ozelius LG, et al. Genetic linkage of von Recklinghausen neurofibromatosis to the nerve growth factor receptor gene. Cell 1987;49:589-94.

6 National Institutes of Health Consensus Development Conference Statement on Neurofibromatosis. Neurofibromatosis Research Newsletter 1987;3:3-6.

7 Huson SM, Harper PS, Compston DAS. Von Recklinghausen neurofibromatosis; a clinical population based hausen neurofibromatosis; a clinical population

8 McGaughran J, Harris DI, Donnai D, et al. A clinical study McGaughran J, Harris DI, Donnai D, et al. A clinical study
of type 1 neurofibromatosis in north west England. $f$ Med Genet 1999;36:197-203.

9 Evans DGR, Huson SM, Donnai D, et al. A genetic study of type 2 neurofibromatosis in the north west of England and the UK: I prevalence, mutation rate, fitness and confirmation of maternal transmission effect on severity. $\mathcal{F} \mathrm{Med}$ Genet 1992;29:841-6.

10 Evans DGR, Huson S, Donnai D, et al. A clinical study of type 2 neurofibromatosis. Q $\mathcal{F}$ Med 1992;84:603-18.

11 Parry DM, Eldridge R, Kaiser-Kupfer MI, Bouzas EA, Pikus A, Patronas N. Neurofibromatosis 2 (NF2): clinical characteristics of 63 affected individuals and clinical evidence for heterogeneity. Am f Med Genet 1994;52:450-1.

12 Parry DM, MacCollin M, Kaiser-Kupfer MI, et al. Germ-line mutations in the neurofibromatosis 2 gene: correlations with disease severity and retinal abnormalities. Am f Hum Genet 1996;59:529-39.

13 Ruttledge MH, Andermann AA, Phelan CM, et al. Type of mutation in the neurofibromatosis type 2 gene (NF2) frequently determines severity of disease. Am f Hum Genet 1996;59:331-42.

14 Evans DGR, Trueman L, Wallace A, Mason S, Strachan T. Genotype phenotype correlations in type 2 neurofibromatosis: evidence for more severe disease with truncating mutations. F Med Genet 1998;35:450-5.

15 Kluwe L, Bayer S, Baser ME, et al. Identification of NF2 germline mutations and comparison with neurofibromatosis 2 phenotypes. Hum Genet 1996;98:534-38.

16 Evans DGR, Wallace A, Trueman L, Wu C-L, Ramsden RT, Strachan T. Mosaicism in classical neurofibromatosis type 2: a common mechanism for sporadic disease in tumor prone syndromes? Am f Hum Genet 1998;63:727-36.

17 Kluwe L, Mautner VF. Mosaicism in sporadic neurofibromatosis 2 patients. Hum Mol Genet 1998;7:2051-5.

18 Evans DGR, Ramsden R, Huson SM, Harris R, Lye R, King TT. Type 2 neurofibromatosis: the need for supraregional care? f Laryngol Otol 1993;107:401-6.

19 Miyamato MT, Campbell RL, Fritsch M, Lochmueller G. Preservation of hearing in neurofibromatosis 2. Otolaryngol Head Neck Surg 1990;103:619-24.

20 Slattery WH, Brackmann DE, Hitselberger W. Hearing preservation in neurofibromatosis type 2. Am f Otol 1998; 19:638-43.

21 Evans DGR, Huson S, Donnai D, et al. A genetic study of type 2 neurofibromatosis: II guidelines for genetic counselling. f Med Genet 1992;29:847-52.

22 Mautner VF, Lindenau M, Baser ME, et al. The neuro-imaging and clinical spectrum of neurofibromatosis 2. Neurosurgery 1996:38:880-5.

23 Evans DGR, Maher ER, Macleod R, Davies DR, Craufurd D. Uptake of genetic testing for cancer predisposition. $\mathcal{F}$ Med Genet 1997;34:746-8.

24 Wu C-L, Neary W, Thakker N, et al. Differential diagnosis of type 2 neurofibromatosis: molecular discrimination of NF2 and sporadic vestibular schwannomas. $\mathcal{F}$ Med Genet 1998;35:973-7. 